\title{
Clinicopathological Profile of Patients with Cervical Lymphadenopathy in a Tertiary Care Centre
}

\author{
Authors \\ Dr Unnikrishnan Edakke Puram ${ }^{1}$, Dr Manjush Edathikudi ${ }^{2 *}$, \\ Dr Mukesh Vaipel Maniyappan ${ }^{3}$ \\ ${ }^{1,2}$ Asst. Professor, General Surgery, Govt. Medical College, Kozhikode \\ ${ }^{3}$ Junior Resident, General Surgery, Govt. Medical College, Kozhikode \\ Corresponding Author \\ Dr Manjush Edathikudi \\ Asst. Professor, General Surgery, Govt. Medical College, Kozhikode
}

\begin{abstract}
In the differential diagnosis of neck swelling, enlargement of cervical lymph nodes is one of the possibilities taken into consideration. Apart from clinical examination, cytological examination contributes to the work up of such cases. However open biopsy has a definite role in selected cases. Of the various causes for enlargement of cervical lymph nodes, tuberculosis has a highest share, followed by other diseases like lymphoma, metastatic carcinoma, etc. We conducted this study to describe the clinicopathological profile of patients presented with cervical lymphadenopathy in the government medical college, kozhikkode. Our study included 100 consecutive cases. Clinical, demographic, cytological and pathlogical features of patients satisfying the inclusion and exclusion criteria were taken in detail. Statistical analysis was done in $R$ statistical environment. Most of the patients belonged to 21 to 30 age group. Most of the patients belonged to 21 to 30 age group. Sixty percent in our study presented with fever. Moreover in young age group tuberculosis forms the commonest cause and in older age group metastasis from occult primary (9 out of 13 cases). On histopathological examination in doubtful cases or other cases which warranted further excision biopsy, 45 cases of reactive hyperplasia diagnosed with fnac on biopsy came as tuberculosis (10).In case of tuberculous lymphadenitis, majority showed a unilateral involvement and the most commonly encountered group was upper cervical. Our study has studied about the clinicopathological profile of the patients presented with cerivical lymph nodes. One of the important findings we found was that tuberculosis still continues to be the most common cause. This has wider socioeconomic implications. In our series, tuberculusois constitued the most common cause for cervical lymphadenopathy on fnac as well as clinically.
\end{abstract}

\section{Introduction}

Enlargement of lymph nodes is one of the possibilities we consider in the differential diagnosis of swellings in the neck ${ }^{1}$. This could present in unilaterally or bilaterally. In most cases, a reasonable diagnosis can be made by clinical examination and cytopathological investigation ${ }^{2-6}$. Since most of the conditions, causing cervical lymph node enlargement is curable, an early achievement of diagnosis and appropriate treatment of the patient should be our aim. Though FNAC has gained more importance as the 
initial investigation, open biopsy still maintains its role in identifying the morphological and structural changes in the gland ${ }^{7-10}$.

The reported causes vary from benign to malignant diseases ${ }^{11-14}$. The causes of lymphadenopathy implicated depend on the age of the patient. In small children, the causes can be head lice or other cutaneous infections of drainage area $^{15-18}$. In older children and young adults, it can be due to tuberculosis or lymphoma, where as in elderly the commonest cause is secondary metastasis. Status of cervical lymph node is the most important prognostic factor in the treatment of patients with squamous-cell carcinoma of the head and neck ${ }^{19,20}$. In most of the studies, tuberculosis contributes to the main cause of the lymphadenopathy ${ }^{18,21-24}$.

The aim of our study was to describe the clinical and cytopathological profile of patients presented with cervical lymph node enlargement. Moreover, we aimed to find out man causes of cervical lymphadenopathy in our centre.

\section{Materials and Methods}

This study was conducted in the department of surgery and ENT department, government medical college, Kozhikkode between 2014 and 2015. Ethics committee approval was obtained before conducting the study. Only those patients wiling to give informed consent were recruited into the study.

The study participants included 100 consecutive patients presenting with discrete asymptomatic cervical lymphadenopathy of more than four-week duration. Only patients above 15 years with lymphadenopathy more than four-week duration and lymph node size more than $10 \mathrm{~mm}$ were included in this study. We excluded those patients currently on treatment and those where the primary was known.

At the time of presentation, a detailed clinical history was taken for each patient for the duration of symptoms and progress of the process. Any history of fever, cough, weight loss, anorexia, contact with an open case of tuberculosis, history of chest, gastrointestinal, head and neck diseases were taken. A stress on past history of tuberculosis was also given.

All cases were examined to see the group of lymph nodes involved, fixity and tenderness. The other groups of lymph nodes were also examined. A thorough examination of scalp, thyroid, oral cavity and ear was also done. A per abdomen examination and examination of testes was also done.

A complete blood count and chest radiography was done in all cases, ENT examination done in relevant cases. Sputum AFB examination done in those patients with respiratory symptoms. Depending upon clinical picture and routine investigations a provisional diagnosis was made. The diagnosis was confirmed by FNAC. When first FNAC was inconclusive, it was repeated a second time. If the result was still inconclusive or as reactive hyperplasia or scanty aspirate, an excision biopsy was done. The data thus obtained was analysed for various causes of lymph node enlargement.

We collected various basic demographic variables and other relevant variables in a pretested data collection form. Various variables collected were age, sex, site, presence of fever and cough and ESR. Details about the clinical diagnosis, fine needle aspiration cytology needle aspiration cytology and histology were abstracted. The data collected were later entered into an excel based database for further analysis.

All statistical analyses were done in R statistical environment. Continuous data were summarized as mean and standard deviation or median with an interquartile range. Categorical data were presented as absolute frequency and percentages.

\section{Results}

This study consisted of a total of 100 cases presented with cervical lymph node enlargement of more than one-month duration. Most of the patients belonged to 21 to 30 age group, followed by $31-40,15-20$ and 50 above. The number of patients in the older age group was comparatively less in this study. Males constituted $60 \%$ of the study group. A swelling was clinically present in 
97 percent of the patients. This study consisted of a total of 100 cases presented with cervical lymph node enlargement of more than one-month duration. Most of the patients belonged to 21 to 30 age group, followed by 31-40, 15-20 and 50 above, followed by middle cervical(29\%), posterior cervical $(21 \%)$ and least affected with the lower cervical(12\%). Sixty percent in our study presented with fever and $79 \%$ with cough. ESR was raised in 70 percent of the patients.

In all the age groups studied, the maximum number of cases were seen in the age group of 1540 (94.9\%). Moreover, in young age group tuberculosis forms the commonest cause and in older age group metastasis from occult primary (9 out of 13 cases).The The exception was papillary carcinoma thyroid. All the 4 cases were below 40 years.

Clinical examination indicated features suggestive of tuberculosis in $34 \%$, metastatic in $13 \%$, lymphoma lymphoma in $12 \%$ and others in 39 percent. However, the FNAC findings showed 29 $\%$ as tuberculosis, 13 as metastatic, 10 as lymphoma, 45 as reactive hyperplasia. A report of scanty aspirate was given in rest of the three patients. Histopathological examination in cases where an excision biopsy was done showed tuberculosis and lymphoma in ten patients each, reactive hyperplasia in 34 patients, sinus histiocytosis and Kikuchi disease in two patients each(table1)

Table 1: Profile of patients with cervical lymphadenopathy diagnosed clinically.

\begin{tabular}{|c|c|c|c|c|c|c|}
\hline & [ALL] $\mathrm{N}=100$ & Tuberculosis N=34 & Metastasis $\mathrm{N}=15$ & lymphoma $\mathrm{N}=12$ & others $\mathrm{N}=39$ & p.over all \\
\hline AGE: & & & & & & 0.007 \\
\hline $15-20$ & $22(22.0 \%)$ & $14(41.2 \%)$ & $0(0.00 \%)$ & $0(0.00 \%)$ & $8(20.5 \%)$ & \\
\hline $21-30$ & $30(30.0 \%)$ & $11(32.4 \%)$ & $2(13.3 \%)$ & $5(41.7 \%)$ & $12(30.8 \%)$ & \\
\hline $31-40$ & $26(26.0 \%)$ & $7(20.6 \%)$ & $7(46.7 \%)$ & $4(33.3 \%)$ & $8(20.5 \%)$ & \\
\hline $41-50$ & $12(12.0 \%)$ & $1(2.94 \%)$ & $3(20.0 \%)$ & $3(25.0 \%)$ & $5(12.8 \%)$ & \\
\hline $51-60$ & $7(7.00 \%)$ & $1(2.94 \%)$ & $3(20.0 \%)$ & $0(0.00 \%)$ & $3(7.69 \%)$ & \\
\hline $61-70$ & $3(3.00 \%)$ & $0(0.00 \%)$ & $0(0.00 \%)$ & $0(0.00 \%)$ & $3(7.69 \%)$ & \\
\hline SEX: & & & & & & 1.000 \\
\hline Male & $60(60.0 \%)$ & $20(58.8 \%)$ & $9(60.0 \%)$ & $7(58.3 \%)$ & $24(61.5 \%)$ & \\
\hline Female & $40(40.0 \%)$ & $14(41.2 \%)$ & $6(40.0 \%)$ & $5(41.7 \%)$ & $15(38.5 \%)$ & \\
\hline SWELLING: & & & & & & 0.048 \\
\hline present & $97(97.0 \%)$ & $34(100 \%)$ & $15(100 \%)$ & $10(83.3 \%)$ & $38(97.4 \%)$ & \\
\hline absent & $3(3.00 \%)$ & $0(0.00 \%)$ & $0(0.00 \%)$ & $2(16.7 \%)$ & $1(2.56 \%)$ & \\
\hline SITE: & & & & & & $<0.001$ \\
\hline submandibular & $2(2.00 \%)$ & $0(0.00 \%)$ & $2(13.3 \%)$ & $0(0.00 \%)$ & $0(0.00 \%)$ & \\
\hline Upper cervical & $36(36.0 \%)$ & $19(55.9 \%)$ & $5(33.3 \%)$ & $5(41.7 \%)$ & $7(17.9 \%)$ & \\
\hline Middle cervical & $29(29.0 \%)$ & $7(20.6 \%)$ & $3(20.0 \%)$ & $4(33.3 \%)$ & $15(38.5 \%)$ & \\
\hline Lower cervical & $12(12.0 \%)$ & $1(2.94 \%)$ & $4(26.7 \%)$ & $3(25.0 \%)$ & $4(10.3 \%)$ & \\
\hline Post. cervical & $21(21.0 \%)$ & $7(20.6 \%)$ & $1(6.67 \%)$ & $0(0.00 \%)$ & $13(33.3 \%)$ & \\
\hline FEVER: & & & & & & $<0.001$ \\
\hline absent & $60(60.0 \%)$ & $11(32.4 \%)$ & $15(100 \%)$ & $8(66.7 \%)$ & $26(66.7 \%)$ & \\
\hline present & $40(40.0 \%)$ & $23(67.6 \%)$ & $0(0.00 \%)$ & $4(33.3 \%)$ & $13(33.3 \%)$ & \\
\hline COUGH: & & & & & & $<0.001$ \\
\hline Absent & $79(79.0 \%)$ & $13(38.2 \%)$ & $15(100 \%)$ & $12(100 \%)$ & $39(100 \%)$ & \\
\hline present & $21(21.0 \%)$ & $21(61.8 \%)$ & $0(0.00 \%)$ & $0(0.00 \%)$ & $0(0.00 \%)$ & \\
\hline ESR: & & & & & & $<0.001$ \\
\hline normal & $30(30.0 \%)$ & $23(67.6 \%)$ & $1(6.67 \%)$ & $4(33.3 \%)$ & $2(5.13 \%)$ & \\
\hline elevated & $70(70.0 \%)$ & $11(32.4 \%)$ & $14(93.3 \%)$ & $8(66.7 \%)$ & $37(94.9 \%)$ & \\
\hline
\end{tabular}

After FNAC, 34 cases which are clinically diagnosed as tuberculosis turned out to be tuberculosis -24 , metastatic -2, lymphoma -1 , and reactive hyperplasia.-7. Fifteen cases which are clinically diagnosed as metastatic lymph node turns out to be, metastatic -10 , tuberculosis -2 , reactive hyperplasia -2 , lymphoma -1 . Twelve cases clinically diagnosed as lymphoma on FNAC, 8 came as lymphoma, 3 as tuberculosis, 1 as metastatic lymph nodes. Thirty nine cases of suspected chronic lymphadenitis, 36 came as reactive hyperplasia, 3 as scanty aspirate. So after 
FNAC, reactive hyperplasia (45) came as common diagnosis made on lymph node aspirates followed by tuberculosis (29), metastatic lymph node (13), lymphoma (10).

Figure1: clinical versus FNAC findings

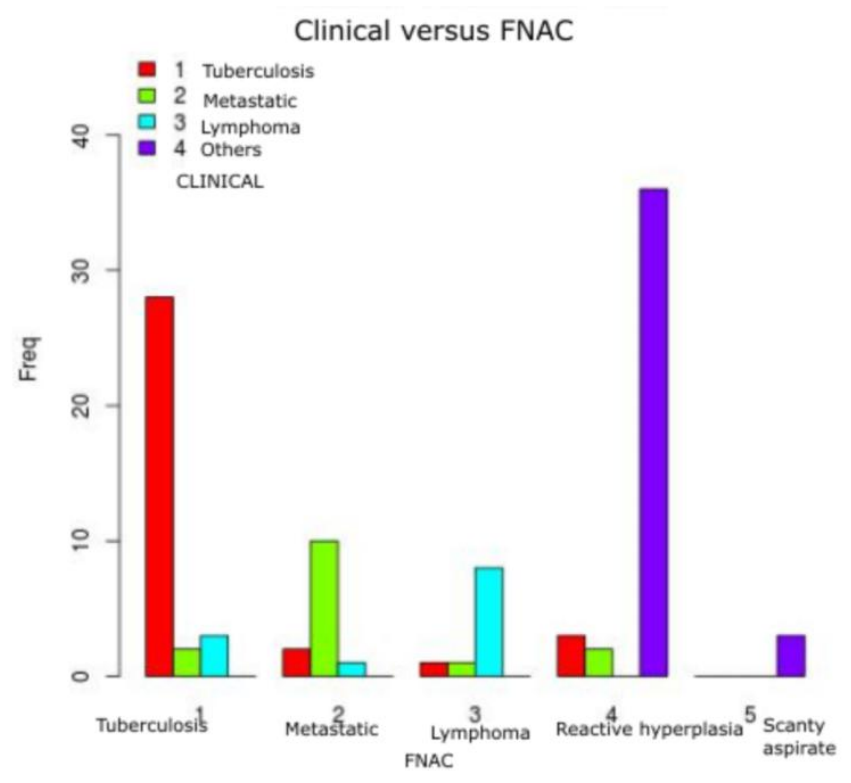

On histopathological examination in doubtful cases or other cases which needed warranted further excision biopsy, 45 cases of reactive hyperplasia diagnosed with fnac on biopsy came as tuberculosis (10), sinus histiocytosis (2), kikuchi lymphadenitis (2), and reactive hyperplasia (31). Ten cases of lymphoma turned out as 7 hodgkin lymphoma and 3 nonhodgkin lymphoma. Scanty aspirate came as reactive hyperplasia.

In case of tuberculous lymphadenitis, majority showed a unilateral involvement, and the most commonly encountered group was upper cervical. In cases of metastatic lymph nodes, upper and middle group were invariably involved. Of lymphoma, Hodgkin's disease was confined to one side and all cases of NHL showed bilateral affection.

\section{Discussion}

In this study, we aimed to describe the clinicopathological profile of the patients coming to our center with cervical lymph node enlargement. In our series, tuberculosis constituted the most common cause for cervical lymphadenopathy on fnac as well as clinically. This finding is comparable to the other literature from Indian subcontinent. Tuberculosis continues to be commonest cause for cervical lymphadenopathy in this part of our country ${ }^{25-28}$. The portal of entry described for Mycobacterium tuberculosis is tonsils. Other rare methods of involvement include adenoids and through retrograde spread from mediastinal nodes to pretracheal and paratracheal and then to the deep cervical lymph nodes. In this study, the most common group involved are upper cervical, followed by middle cervical. It shows that in most cases portal of entry of myco bacterium tuberculosis is tonsil. Other studies also agree with this observation. The other groups are also involved; it may be due to skip involvement of lymph node regions or by retrograde spread from mediastinal nodes. Ear nose throat examination was normal in cases, and no primary foci were found. This is well in accordance with literature where only rarely after tonsillectomy was a focus found in the tonsils 26. Of the 39 cases of tuberculous lymphadenitis, 23 males and 16 females were affected. In all the age group studied, the maximum number of cases was seen in the age group of 15-40 (94.9\%). so So it is clear that in young age group, tuberculosis forms the commonest cause.

20 patients had respiratory tract involvement in the form of cough. None had hemoptysis. 27 had evening rise of temperature. None had history of tuberculosis.

Haematological investigations were very much contributory to the diagnosis of tuberculous lymphadenitis. Majority had an increased ESR and relative lymphocytosis even though the total leukocyte count was within normal limits. Sputum was examined in relevant cases, but AFB was not demonstrated in any of them. FNAC was found to be very useful to establish the diagnosis. It was the confirmatory investigation of choice, and results could be obtained in 72 hours.

The prevalence of reactive hyperplasia as per the fnac results was higher in our study. However, when these cases underwent excision biopsy of 
the nodes, many of the cases turned out to be tuberculosis, with reactive hyperplasia still being the largest subcategory. The prevalence of reactive hyperplasia in neck nodes in the literature varies up to 20 percent $^{29}$. This condition resolves spontaneously without any treatment in one-third of the patients. However, there could be an underlying pathology like tuberculosis in onefourth of the patients with the rest in need of prolonged treatment. In our series, the prevalence of reactive hyperplasia was higher compared to other studies. This need furthers investigation. Metastatic lymph node formed the third commonest cause of cervical lymph node enlargement in the present study. Literature suggests it as the fourth commonest cause ${ }^{30}$. Majority of these patients were below forty years, whereas literature shows a preponderance in the elderly group. This could be due to the difference in the location of the primary tumor in western population. In the present study, the majority of the cases were contributed by squamous carcinoma, followed papillary carcinoma. Previous studies showed that in $70-85 \%$ of cases, the cytopathology is squamous-cell carcinoma ${ }^{3133}$.

The prevalence pattern observed during our study need not to reflect the actual pattern in the society as our study was a hospital-based study with preferential reference of high-risk cases to our institution.

Our study has studied in detail about the clinicopathological profile of the patients presented with critical lymph nodes. One of the important findings we found was that tuberculosis still continues to be the most common cause. This has wider socioeconomic implications.

\section{Reference}

1. Balm A, van Velthuysen M, Hoebers F, Vogel W, van den Brekel M. Diagnosis and treatment of a neck node swelling suspicious for a malignancy: an algorithmic approach. International journal of surgical oncology 2010; 2010.

2. Woolgar JA, Beirne J, Vaughan E, LewisJones H, Scott J, Brown J. Correlation of histopathologic findings with clinical and radiologic assessments of cervical lymphnode metastases in oral cancer. International journal of oral and maxillofacial surgery 1995; 24(1): 30-7.

3. Chao S, Loh K, Tan K, ... Tuberculous and nontuberculous cervical lymphadenitis: a clinical review._-Head and Neck ... 2002.

4. Kline T, Kannan V, Kline I. Lymphadenopathy and aspiration biopsy cytology. Review of 376 superficial nodes. Cancer 1984.

5. Brekel MVd, Castelijns J, Stel H, ... Modern imaging techniques and ultrasound-guided aspiration cytology for the assessment of neck node metastases: a prospective comparative study. European Archives of ... 1993.

6. Som P. Detection of metastasis in cervical lymph nodes: CT and MR criteria and differential diagnosis. AJR American journal of roentgenology 1992.

7. Atula T, Varpula M, Kurki T, Klemi P, ... Assessment of cervical lymph node status in head and neck cancer patients: palpation, computed tomography and low field magnetic resonance imaging compared ...European journal of ... 1997.

8. Bezabih M, Mariam D, Selassie S. Fine needle aspiration cytology of suspected tuberculous lymphadenitis. Cytopathology 2002.

9. Lau S, Wei W, Hsu C, ... Efficacy of fine needle aspiration cytology in the diagnosis of tuberculous cervical lymphadenopathy. The Journal of ... 1990.

10. Brekel MVd, Castelijns J, Stel H, Luth W, ... Occult metastatic neck disease: detection with US and US-guided fineneedle aspiration cytology. Radiology 1991.

11. Becker W. Diseases Of The Cervical Lymph Nodes. Anatomy, Differential Diagnosis and Therapy: europepmc.org; 1964. 
12. Matsushita Y. Diagnosis and therapy of tuberculosis in the cervical lymph nodes: europepmc.org; 1966.

13. Willam C, Mäurer J, Steinkamp H, Vogl $\mathrm{T}, \ldots$ Differential diagnosis of cervical lymph node enlargements: ultrasound and histomorphology of reactive lymph nodes. Bildgebung $=\ldots 1996$.

14. Takeuchi Y, Suzuki H, Omura K, Shigehara $\mathrm{T}, \ldots$ Differential diagnosis of cervical lymph nodes in head and neck cancer by ultrasonography. Auris Nasus ... 1999.

15. Leung AK, Davies HD. Cervical lymphadenitis: etiology, diagnosis, and management. Curr Infect Dis Rep 2009; 11(3): 183-9.

16. Annam V, Kulkarni MH, Puranik RB. Clinicopathologic profile of significant cervical lymphadenopathy in children aged 1-12 years. Acta Cytol 2009; 53(2): 174-8.

17. Citak EC, Koku N, Demirci M, Tanyeri B, Deniz H. A retrospective chart review of evaluation of the cervical lymphadenopathies in children. Auris, nasus, larynx 2011; 38(5): 618-21.

18. Rajasekaran K, Krakovitz P. Enlarged neck lymph nodes in children. Pediatric clinics of North America 2013; 60(4): 92336.

19. Snow G, Annyas A, Slooten Ev, Bartelink H, Hart A. Prognostic factors of neck node metastasis. Clinical Otolaryngology 1982; 7(3): 185-92.

20. Mamelle G, Pampurik J, Luboinski B, Lancar R, Lusinchi A, Bosq J. Lymph node prognostic factors in head and neck squamous cell carcinomas. The American journal of surgery 1994; 168(5): 494-8.

21. Thakkar K, Ghaisas SM, Singh M. Lymphadenopathy:

Differentiation between Tuberculosis and Other NonTuberculosis Causes like Follicular Lymphoma. Frontiers in Public Health 2016; 4.
22. Malhotra AS, Lahori M, Nigam A, Khajuria A. Profile of Lymphadenopathy: An Institutional Based Cytomorphological Study. International journal of applied \&amp; basic medical research 2017; 7(2): 100-3.

23. Qadri SK, Hamdani NH, Shah P, Lone MI, Baba KM. Profile of lymphadenopathy in Kashmir valley: a cytological study. Asian Pacific journal of cancer prevention : APJCP 2012; 13(8): 3621-5.

24. Ondounda M, Gaudong Mbethe L, Mounguengui D, Magne C, Nzenze JR. [Profile of adenopathies in a tropical setting: 78 observations in Gabon]. Medecine et sante tropicales 2013; 23(3): 304-7.

25. Prasad KC, Sreedharan S, Chakravarthy Y, Prasad SC. Tuberculosis in the head and neck: experience in India. The Journal of Laryngology \& Otology 2007; 121(10): 979-85.

26. Jha B, Dass A, Nagarkar N, Gupta R, Singhal S. Cervical tuberculous lymphadenopathy: changing clinical pattern and concepts in management. Postgraduate medical journal 2001; 77(905): 185-7.

27. Dandapat M, Mishra B, Dash S, ... Peripheral lymph node tuberculosis: a review of 80 cases. British Journal of ... 1990.

28. Sharma S, Mohan A. Extrapulmonary tuberculosis. Indian Journal of Medical Research 2004.

29. Ahmad I. Non-specific reactive hyperplasia of cervical lymph nodes: a follow-up. J Pak Med Assoc 1992; 42(10): 237-8.

30. Mohseni S. Peripheral Lymphadenopathy: Approach and Diagnostic Tools. 2014; 39(2 Suppl): 158-70.

31. Sanderson RJ, Ironside JAD. Squamous cell carcinomas of the head and neck. Bmj 2002; 325(7368): 822-7. 
32. Geurts TW, Nederlof PM, van den Brekel MW, et al. Pulmonary squamous cell carcinoma following head and neck squamous cell carcinoma: metastasis or second primary? Clinical cancer research : an official journal of the American Association for Cancer Research 2005; 11(18): 6608-14.

33. Umeda M, Yokoo S, Take Y, Omori A, Nakanishi K, Shimada K. Lymph node metastasis in squamous cell carcinoma of the oral cavity: correlation between histologic features and the prevalence of metastasis. Head Neck 1992; 14(4): 26372 . 